\title{
Bankacılık Endeksi İle Seçilmiş Makroekonomik Faktörler Arasındaki Asimetrik İlişki
}

Eyyüp Ensari ŞAHİN ${ }^{1}$

\begin{tabular}{ccc}
\hline $\begin{array}{c}\text { Geliş Tarihi/ Received } \\
24 / 01 / 2020\end{array}$ & Kabul Tarihi/ Accepted & Yayın Tarihi/ Published \\
$18 / 03 / 2020$ & $15 / 04 / 2020$ \\
\hline Citation/Atıf: Sahin E E & $2020)$ Bankaclık Endeksi ile Secilmis Makroekonomik Faktörler
\end{tabular}

Citation/Atıf: Şahin, E. E., (2020), Bankacılık Endeksi ile Seçilmiş Makroekonomik Faktörler Arasındaki Asimetrik İlişki, Atatürk Üniversitesi İktisadi ve İdari Bilimler Dergisi, 34(2): 351369, DOI: 10.16951/atauniiibd.679812

Öz: Hisse senedinin fiyatı gelecekte sağlayacağı nakit akıșının iskonto edilmiş haline eşittir. İskonto oranı ise genellikle piyasa faiz oranı (risksiz faiz oranı) ve risk primine bağlı olarak değişmektedir. Ancak hisse senetleri alım satımın yapıldığ 1 pazarın etkinlik durumuna göre de değişmektedir. Etkin piyasalar hipotezine göre zayıf formda etkin piyasalarda piyasaya yansıyan bilgiler fiyatlar üzerinde etkili olabilmektedir. Bu çalışma da BİST Bankacılık Endeksine etki etmesi beklenen seçilmiş makroekonomik değişkenler ile analiz yapılmıştır. Analiz dönemi 2005/01-2019/12 yılları arası aylık verilerden oluşmaktadır. Çalışmada değişkenler arası asimetrik etkiyi belirlemek amacıyla Doğrusal Olmayan Gecikmesi Dağıtılmış Oto Regresif Model (NARDL) kullanılmıştır. Çalışmanın sonucunda ise Bankacılık endeksi ile Dolar, Euro ve CDS, VIX, Altın uzun dönemli ve kısa dönemli asimetrik bir ilișki bulunmuştur.

Anahtar Kelimeler: Bankacılık Endeksi, CDS, Altın, VIX, NARDL

Asymmetric Relatıonship between The Banking Index and Selected Macroeconomic Factors

Abstract: The price of the stock is equal to the discounted version of the future cash flow. The discount rate generally depends on market interest rate (risk-free interest rate) and risk premium. However, the stocks also change according to the efficiency of the market in which they are traded. According to the active markets hypothesis, the information reflected in the markets in weak form in active markets may affect prices. In this study, selected macroeconomic variables that are expected to affect the BIST Banking Index are analyzed. The analysis period consists of monthly data between 2005/01-2019/12. In this study, Nonlinear Delay Distributed Auto Regressive Model (NARDL) was used to determine the asymmetric effect between variables. As a result of the study, a long-term and short-term asymmetric relationship was found with the Banking index, Dollar, Euro and CDS, VIX, Gold.

Keywords: Banking Index, CDS, Gold, VIX, NARDL

${ }^{1}$ Dr. Öğretim Üyesi, Hitit Üniversitesi, İktisadi ve İdari Bilimler Fakültesi, Uluslararası Ticaret ve Lojistik Yönetimi Bölümü, https://orcid.org/0000-0003-2110-7571 


\section{EXTENDED SUMMARY}

Background: Equity price fluctuations are frequently followed by stock investors and the economies of countries in need of external financing. In particular, the direction of prices has been the subject of many studies. Investors follow the stock price movements and try to determine the factors affecting the prices and the changes that may occur in these factors through various statistical, mathematical and econometric studies. The price of the stock is equal to the discounted version of the future cash flow. The discount rate generally varies depending on the market interest rate (risk-free interest rate) and risk premium Therefore, it can be said that the price of stocks is a function of interest rate which has a significant effect on the formation of market conditions and many macroeconomic variables. When the studies carried out in the literature are examined, it is found that macroeconomic variables affect stock returns by affecting both expected cash flows and discount rates.

Purpose: In this study, selected macroeconomic variables that are expected to affect the BIST Banking Index are analyzed. The analysis period consists of monthly data for the years 2005 / 01-2019/12. In this study, Nonlinear Delay Distributed Auto Regressive Model (NARDL) was used to determine the asymmetric effect between variables.

Method: In order to test whether there is a short and long term asymmetric passivity between dependent and independent variables used in the study, Shin et al. (2014) Nonlinear Delay Distributed Auto Regressive Model (NARDL) was used. The NARDL approach focuses on the short- and long-term asymmetric relationship between variables, and the effects of "negative" and "positive" changes in independent variables on the dependent variable are determined.

Findings: Descriptive statistics of the variables are given first from the analysis results. According to the results given in Table 3, Index value, which is the dependent variable of the study, has the highest average. Before estimating the NARDL model, it should be ensured that the variables used in the model do not have an integration degree of I (2), otherwise the predicted model results may be spurious. In Table 4, the estimated unit root test results of the relevant variables were analyzed with the help of Augmented Dickey-Fuller (ADF) test. According to the results obtained, it is seen that all of the variables are stationary at level. After checking the unit roots of the variables, whether there is cointegration between the variables in the long term and short term was examined with the help of the Wald test. The lower and upper limit values calculated by Narayan (2005) and the $\mathrm{F}$ statistical values used to determine the presence of cointegration are given in Table 5.

Conclusions: According to the research presented, we suggest that it is necessary to address and develop more transparent pathways through education, and find new ways of solving the problem of a lack of apprenticeships. There is 
a need to According to the active markets hypothesis, the information reflected in the markets in weak form in active markets may affect prices. Accordingly, stocks can be affected by macroeconomic variables. In literature review, studies conducted between macroeconomic variables and stock price differ. The main reason for these differences can be explained as the analysis methods used and the activity form of the country's market. Poor form active stock prices in Turkey may be affected by the information disclosed to the public. In this context, the closing prices of Borsa İstanbul Banking Index and selected macroeconomic variables have been tested with the Nonlinear Delay Distributed Auto Regressive Model (NARDL) model in order to test the accuracy of this theory and to measure the possible effects of variables on the banking index. The variable made on the banking index was kept positive and negative. Interest rate, Inflation rate, Total Loans and Total deposits used as control variables are excluded from this distinction. Banking index, which is important in Equation 4, includes a longterm asymmetrical relationship that is divided into Dollars $(-0,534)$, Euro ($0,0774)$, CDS $(-0,386)$, VIX $(-0,047)$ and Gold $(-0,005)$. CDS $(-0.682)$, VIX $(-$ $0.095)$, Gold (-0.693), Dollar (-0.2525), Euro (-0.036) long-term asymmetric relationship has been found. Short-term, asymmetrical relationship process in the study (Layenge and Zumwalt, 1980; Booth and Officer 1985; Akella and Chen 1990; Scott and Peterson, 1986).

\section{Giriş}

Hisse senetleri fiyat değişkenliği hisse senedi yatırımcısı ve dış finansmana ihtiyacı olan ülke ekonomi yönetimleri tarafından sıklıkla takip edilmektedir. Özellikle fiyatlarının ne yönde seyredeceği birçok çalışmanın konusunu oluşturmuştur. Yatırımcılar Hisse senetleri fiyat hareketlerini takip ederek çeşitli analizler ile fiyatlara etki eden faktörleri ve bu faktörlerde meydana gelebilecek değişimleri çeşitli istatistiksel, matematiksel ve ekonometrik çalışmalar ile belirlemeye çalışırlar(Syzdykova, 2018: 2). Hisse senedinin fiyatı gelecekte sağlayacağı nakit akışının iskonto edilmiş haline eşittir. İskonto oranı ise genellikle piyasa faiz oranı (risksiz faiz oranı) ve risk primine bağlı olarak değişmektedir(Özer vd., 2011,164). Bu sebepten hisse senetlerinin fiyatı piyasa koşulları oluşumunda önemli bir etkiye sahip faiz oranı ve beraberinde birçok makroekonomik değişkenin bir fonksiyonu olduğu söylenebilir. Chen, Roll, v.d., (1986), Fama, (1981), Scott ve Peterson (1986), Fogler, John ve Tipton (1981), Lynge ve Zumwalt (1980) ve Chance and Lane (1980) yılında yaptıkları çalışmada Makroekonomik değişkenlerin hem beklenen nakit akışlarını hem de iskonto oranlarını etkilemek suretiyle hisse senedi getirilerini etkilediği saptanmıştır. Bu çalışmalar içerisinde özellikle ülkemizde lokomotif bir sektör görevi gören bankacılık endeksi Basel 2.5 kriterleri ile güçlü bir yapıya kavuşmuş olup, güçlü yapısı sayesinde hisse senedi yatırımcıları tarafından hisse senedi fiyatlarının değişimi yakından takip edilmektedir. Banka hisse senetlerinin faiz, altın, CDS vb. makroekonomik değişken duyarlılığı konusunda literatürde çeşitli 
çalışmalar yapılmıştır. Booth ve Officer (1985), Akella ve Chen, (1990), Isimbabi, (1993), Dickens vd., 1994), Joseph ve Vezos, (2006), Ryan ve Worthington, (2014), y1lında Banka hisse senetleri ile makroekonomik değişkenler arasındaki ilişkiyi incelemişlerdir. Bu çalışmanın amacı 2005- 2019 yılları arasında aylık veriler kullanılarak Bankacılık Endeksi ile CDS, Altın, Döviz Kuru, VIX, Enflasyon, Faiz Oran1, Toplam Krediler, Toplam Mevduat arasındaki asimetrik bir ilişkinin varlığının tespiti amaçlanmıştır. Çalışma sonucunda kullanılan değişkenlerin bankcalık endeksi fiyatı ile asimetrik ilşkisinin varlığı tespit edilmiştir.

\section{Bankacılık Sektörü}

Ekonomik büyümenin ülkeler açısından önemi hayli yüksektir. $\mathrm{Bu}$ kapsamda ülke ekonomileri için finansal piyasalar büyümeye yardımcı olan özelliği ile günümüz teknoloji dünyasında öne çıkmaktadır. Finansal sistem içerisinde bankacılığın rolü aracılık işlevi yanı sıra paranın piyasa da dolaşımını sağlamasıdır. Paranın dolaşımı ulusal olabileceği gibi uluslararası boyuta da öne çıkmıştır. Türkiye de bankacılık sektörü 1980'li yıllardan sonra artış göstermiş ve 1990'lı yıllardan sonra küresel para akışına aracılık edebilecek kurumlara dönüşmüştür. Türkiye gibi gelişmekte olan ülkeler için bankacıllk sektörü devletin sürekli kontrolünde ve denetiminde bulunmaktadır. Bankacilık sektöründe meydana gelebilecek herhangi bir olumsuz olay firmalara hemen yansiyacak buda ülke ekonomisine olumsuz etkileyecektir. Tablo1'de Türkiye' de mevcut bankaların faaliyet alanlarına göre ayrımı verilmektedir.

Tablo1: Türkiye'de Faaliyet Gösteren Banka Sayısı

\begin{tabular}{lccccc}
\hline & 2014 & 2015 & 2016 & 2017 & 2018 \\
Mevduat Bankaları & $\mathbf{3 4}$ & $\mathbf{3 4}$ & $\mathbf{3 4}$ & $\mathbf{3 4}$ & $\mathbf{3 4}$ \\
Kamusal Sermayeli & 3 & 3 & 3 & 3 & 3 \\
Özel Sermayeli & 11 & 11 & 9 & 9 & 9 \\
Yabanc1 Sermayeli & 19 & 19 & 21 & 21 & 21 \\
Tas.Mevd.Sig.Fonu. Devr. & 1 & 1 & 1 & 1 & 1 \\
Kalkıma ve Yatırım Bankaları & $\mathbf{1 3}$ & $\mathbf{1 3}$ & $\mathbf{1 3}$ & $\mathbf{1 3}$ & $\mathbf{1 3}$ \\
Katılım Bankaları & $\mathbf{4}$ & $\mathbf{5}$ & $\mathbf{5}$ & $\mathbf{5}$ & $\mathbf{5}$ \\
Toplam & $\mathbf{5 1}$ & $\mathbf{5 2}$ & $\mathbf{5 2}$ & $\mathbf{5 2}$ & $\mathbf{5 2}$ \\
\hline
\end{tabular}

Kaynak: www.tbb.org.tr/tr

Bankacılık sektöründe 2019 tarihi itibari ile Mevduat bankası sayısı 34, Kalkınma ve yatırım bankası 13 adet, katılım bankası 5 adet olmak üzere toplam 52 adet banka faaliyet göstermektedir. Mevcut 54 bankanın piyasadaki rolü ise finansal aracıllk, likitide yaratmak, kredi taleplerini izlemek ve değerlendirmek, ekonomik istikrara katkıda bulunmak, para politikalarının etkinliğini arttırmak, ödeme sistemlerinin etkinliğini arttırmak, Dış ticareti fonlamak, ihracatı teşvik etmek ve finansal katılımı arttırmak şeklinde sıralanabilir. Türk bankacılık 
sektörünün aktif yapısı değerlendirildiğinde Tablo2'de görüldüğü üzere (20142018) iki kat bir artış gözlenmektedir.

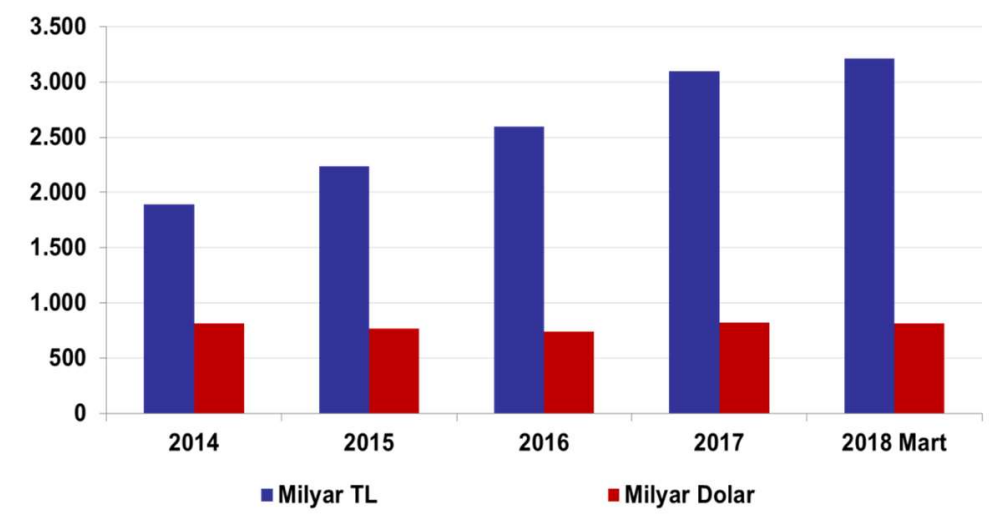

Grafik 1. Bankaların Aktif Toplamı

İçinde bulunduğumuz dönem itibari ile bankalar gerek para piyasası gerekse finansal piyasalar için oldukça etkin bir rol üstlenmektedir. Mevcut konumu itibari ile bankalar hem bireysel işlemler hem de ticari faaliyetlerde birçok farklı ürün seçeneği ile paydaş olabilmektedir. Bu ürünlerin sürekliliği ve sürdürülebilirliği açısından bankalar yeterli mevduata sahip olmalıdır. Yeterli mevduatı toplayabilmek için güven unsuru önemli bir etkendir. Bu açıdan değerlendirildiğinde Türk bankacılık sistemi Basel I, II ve III kriterlerini yerine getirerek piyasada güçlü ve güvenilir bir pozisyona yükselmeyi başarabilmiştir. Grafik 2'de Türk Bankacılık sektörü toplam mevduatının yıllara göre değişimi gösterilmiştir.

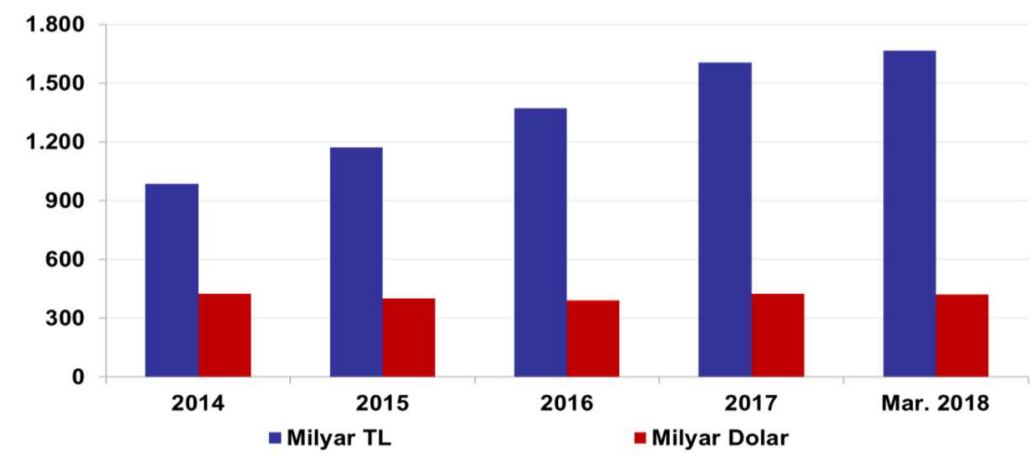

Grafik 2. Bankaların Mevduat Toplamı

Grafik 2 incelendiğinde bankacılık sektörü toplam mevduatın 2014 yılından günümüze iki kat arttığ1 görülmektedir. Tablo2 ve Tblo3 de verilen 
artışların bankacılık sektörü için önemi yüksektir. Bu bankalara olan güveni ve bankaların hisse senedi fiyatlarını olumlu yönde etkileyebilmektedir.

\section{Literatür}

Hisse senedi getirileri ve makroekonomik değişkenler üzerine literatürde farklı metotlar ve değişkenler kullanılarak birçok çalışma yapılmıştır. Çalışmalarda kullanılan veri seti, örneklem ve yöntemden dolayı farklı sonuçlar çıkmıştır. Bu kapsamda öncelikle yapılan çalışmalar farklı veri tabanlarından araştırılarak yapıldığı ülkeler dünya haritası üzerinde gösterilmiştir.

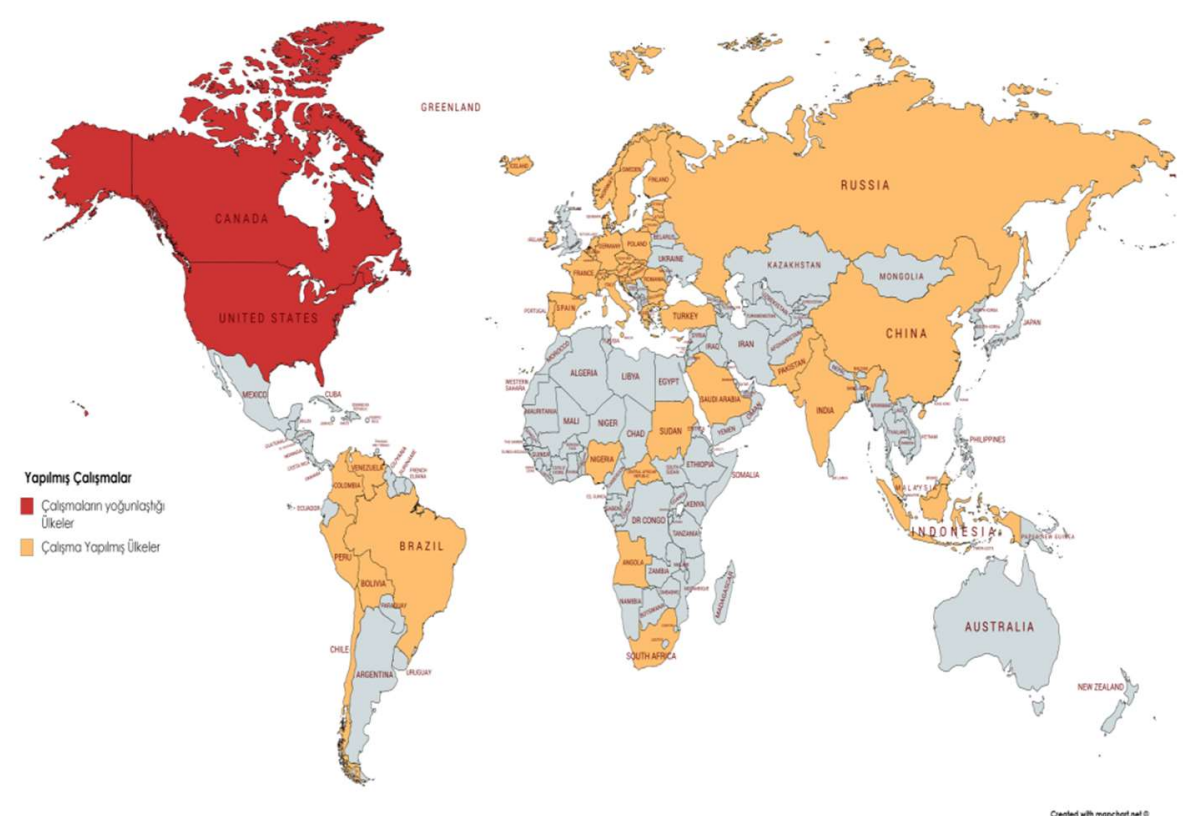

Şekil 1. Bankacılık Endeksi Üzerine Yapılmış Çalışmalar

Bankacılık hisse senetleri üzerine yapılmış çalışmalar özellikle ABD ve Kanada' da yoğun olarak yapılmış olup, günümüze yaklaştıkça diğer ülkelerde de yapıldığı görülmektedir. Özellikle gelişmekte olan ülkelerde ve ASEAN (Güneydoğu Asya Uluslar Birliği) topluluğu olarak bilinen ülkelerde son dönemde yapılmış çalışmalar bulunmaktadır. Çalışmanın bu bölümünde özellikle farklı değişken ve yöntem kullanan çalışmalara yer verilmiştir.

Moss J. ve Moss G. (2010) yaptıkları çalışmada faiz oranı, dolar altın, VIX verileri ile Bankacılık Endeksi verileri arasındaki ilişkiyi incelemişlerdir. Çalışma verileri 1998 - 2009 arasında haftalık olarak kullanılmıştır. Çalışmada 
Regresyon yöntemi kullanılmış olup, Bankacılık Endeksi fiyatını kullanılan değişkenlerin açıklama gücünün yükssek olduğu soncuna ulaşmışlardır.

Ryan ve Worthington (2004) yılında yaptıkları çalışmada Avustralya banka hisse senedi getirileri ile faiz oranları, döviz kuru arasındaki ilişkiyi incelemişlerdir. Çalışmanın verileri 1996- 2001 yılları arasında haftalık verilerden oluşmaktadır. Genelleştirilmiş Otoregresif Koşullu Değişen Varyans yöntemi (GARCH-M) kullanılmıştır. Kısa ve orta vadeli faiz oranlarının banka hisse senedi fiyatının belirleyicisi olduğunu sonucuna ulaşmışlardır.

Sharma ve Mahendru (2010) yılında yaptıkları çalışmada Hindistan bankacılık endeksi ile makroekonomik değişkenler arasındaki ilişkiyi incelemişlerdir. Çalışma verileri 2008 - 2009 yılını kapsamakta olup regresyon analizi yöntemini kullanmışlardır. Çalışma sonucunda döviz kurundaki değişim, dış döviz rezervi, enflasyon oranı ve altın fiyatı arasında ilişki bulunmuştur.

Lee (1992) yılında yaptığı çalışmada ABD bankacılık hisse senedi fiyatları ile makroekonomik değişkenler arasındaki ilişki incelenmiştir. Çalışma sonucunda hisse getirileri ile faiz oranları arasında ilişki bulunmuş olup enflasyon ile banka hisse senedi getirileri arasında düşük bir ilişki bulmuştur.

Özer vd. (2011) yılında yaptıkları çalışmada BİST 100 Endeksi ile makroekonomik değişkenler arasındaki ilişkiyi incelemişlerdir. Çalışmanın veri seti 1996 - 2009 yılları arasında aylık verilerden oluşmaktadır. Çalışmanın yöntemi En Küçük Kareler Tahmin yöntemi, Johansen-Juselius Eşbütünleşme Testi, Granger Nedensellik Testi ve VEC modelleridir. Çalışmanın sonucunda hisse fiyatları ile faiz oranı, para arzı, dış ticaret dengesi ve sanayi üretim endeksi değişkenleri arasında uzun dönemli bir ilişkinin varlığını sonucuna ulaşmışlardır.

Syzdykova (2018) yılında yaptığı çalışmada Kazakistan- KASE hisse senedi fiyatları ile seçilmiş makroekonomik faktörler arasındaki istatistiksel açıdan anlamlılığını tespit etmek için En Küçük Kareler yöntemi, değişkenler arasındaki uzun dönemli ilişkinin varlığını araştırmak için Johansen eşbütünleşme testi, değişkenler arasındaki nedenselliğin açıklanması için hata düzeltme modeli ve Granger nedensellik analizi kullanılmıştır. Çalışma sonucunda faiz oranı, sanayi üretim endeksi, döviz kuru, TÜFE ve petrol fiyatları değişkenlerinde meydana gelen değişimler Kazakistan borsasını \%62 oranında açıklamakta olduğu sonucuna ulaşmışlardır.

Patra ve Poshakwale (2006) yaptıkları çalışmada Yunanistan Atina borsası hisse senedi fiyatı ile makroekonomik değişkenler arasındaki ilşkiyi incelemişlerdir. Çalışmada 1990- 1999 yılları arasında aylık veriler kullanılmışır. Çalışma sonucunda makroekonomik değişkenlerin borsa fiyatlarını açıklamakta kullanılabileceğini savunmuşlardır.

Al-Jafari vd. (2011) yaptıkları çalışmada gelişmekte olan piyasa borsa verilerini kullanmışlardır. Çalışma verileri 2002- 2008 yılları arası aylık veriler olup, hisse senetleri kapanış fiyatı ile makroekonomik değişkenlerden oluşmaktadır. Reel ekonomik aktivite düzeyi ve gelişmiş piyasalardaki hisse senedi fiyatları arasında uzun vadede olumlu bir ilişki olduğu bulunmuştur. 


\section{Veri ve Yöntem}

Literatürde en sık kullanılan eşbütünleşme testleri, hata terimine dayalı iki aşamalı Engle-Granger (1987) yöntemi ile sistem yaklaşımına dayalı Johansen (1988) ve Johansen ve Jesulius (1990) yöntemidir (Koçbulut ve Altıntaş, 2016:8). Pesaran,vd. (2001) yılında yaptıkları çalışmada bu yöntemlerin uygulanabilmesinin önkoşulunu serilerin durağan olması gerektiğine bağlamışlardır. Çalışmada kullanılan bağımlı ve bağımsız değişkenler arasında kısa ve uzun dönemli bir asimetrik geçişkenliğin olup olmadığını test etmek için, Shin vd. (2014) tarafından geliştirilen Doğrusal Olmayan Gecikmesi Dağıtılmış Oto Regresif Model (NARDL) kullanılmıştır.

NARDL modeli diğer modellere göre bazı üstünlüklere sahiptir. Modelin üstünlüğ̈̈, koentegrasyon dinamiklerini ve asimetrik (doğrusal olmayan) ilişkiyi aynı anda modellemesi bakımından literatürde kullanılan diğer doğrusal ve doğrusal olmayan koentegrasyon yöntemlerine (hata düzeltme modeli (ECM), eşik hata düzeltme modeli ve markov rejim değişimi hata düzeltme modeli) yönünden öne çıkmaktadır. Ayrıca, NARDL yaklaşımında regresörlerin aynı derecede bütünleşmeleri zorunluluğu, yani değişkenlerin hem I(0) hem de I(1) düzeyinde (I(2) hariç), bulunmamaktadır (Pesaran ve Shin, 1998). Peseran ve Shin (1999) ve Pesaran, Shin, vd. (2001) tarafından geliştirilmiş ve literatürde çok sık kullanılan doğrusal ARDL modeli, son yıllarda Shin, Yu, vd. (2014) tarafindan asimetrik ilişkileri dikkate alacak şekilde daha da geliştirilmiş ve literatüre NARDL modeli olarak kazandırılmıştır (Çıtak ve Kendirli, 2019:650). NARDL yaklaşımı değişkenler arasındaki kısa ve uzun dönem asimetrik ilişki üzerine odaklanmış olup bağımsız değişkenlerde meydana gelen "negatif" ve "pozitif" değişmelerin bağımlı değişken üzerinde oluşturduğu etkiler belirlenmektedir

Çalışmada, Data Stream veri tabanından alınan 2005:01- 2019:12 yılları arası aylık veriler kullanılarak, seçilmiş bazı makroekonomik (Dolar/Türk Lirası, Euro/Türk Lirası, Altın Fiyatları, Enflasyon ve Faiz oranı) değişkenler, Risk Değişkeni olarak VIX ve CDS gibi değişkenlerin Borsa İstanbul Bankacılık Endeksi Getirileri üzerine asimetrik etkisi incelenmiş̧ir. Ayrıca, çalışmada kontrol değişkenler olarak "Bankalardaki Toplam Mevduat ve Verilen Kredilerin Toplamı” kullanılmıştır.

Tablo 2: Çalışmanın Bağımlı ve Bă̆ımsız Değişkenleri

\begin{tabular}{lll}
\hline Değişkenler & Veri Tabanı & Dönem \\
\hline Banka Endeksi & Data Stream & $2005 / 01-2019 / 12$ \\
\hline Dolar & EVDS & $2005 / 01-2019 / 12$ \\
\hline Euro & EVDS & $2005 / 01-2019 / 12$ \\
\hline Altın & EVDS & $2005 / 01-2019 / 12$ \\
\hline Enflasyon Oranı & EVDS & $2005 / 01-2019 / 12$ \\
\hline Faiz Oranı & EVDS & $2005 / 01-2019 / 12$ \\
\hline VIX & Data Stream & $2005 / 01-2019 / 12$ \\
\hline CDS & Data Stream & $2005 / 01-2019 / 12$ \\
\hline
\end{tabular}


Tablo 2 Devamı: Çalışmanın Bağımlı ve Bağımsız Değişkenleri

\begin{tabular}{lll}
\hline Kontrol Değişkenler & & \\
\hline Toplam Mevduat & EVDS & 2005/01-2019/12 \\
\hline Verilen Kredi Toplamı & EVDS & $2005 / 01-2019 / 12$ \\
\hline
\end{tabular}

Çalışmada bağımlı değişken olarak, Bankacılık Endeksi kullanılmıştır. Borsa İstanbul Bankacılık Sektörünü temsil eden Bankacılık Endeksi kapanış fiyatları 2005/01-2019/12 dönemi aylık verilerden oluşmaktadır. Çalışmamızın bağımsız değişkenlerinden ilki Dolar/TL ve Euro/TL olarak belirlenmiştir. Literatürde oldukça sık kullanılmış olup, gelişmekte olan ekonomilerde alternatif yatırım aracı olarak belirlendiği için negatif yönlü anlamlı sonuçlar bulunmuştur (Doğukanlı, 2008: 49). Altın ise literatürde kullanılan diğer bir bağımsız değişken olarak karşımıza çıkmaktadır. Yapılan çalışmalarda Altın güvenli bir liman olarak belirlenmiş özellikle risk ve belirsizlik ortamında yatırımcıların hisse senetleri yerine altına yöneldikleri görülmüştür (Elyak, 2008:39). Enflasyon ve faiz oranı ise çalışmanın önemli birer bağımsız değişkenidir. Yatırımcının piyasadan beklediği minimum getiri oranı piyasa faiz oranı kadardır. $\mathrm{Bu}$ kapsamda yatırımcılar genellikle riskten kaçınmak istedikleri dönemlerde ve faiz oranlarının yükseldiği dönemlerde yatırımlarını vadeli mevduata kaydırmaktadırlar. Bunun sebebi yatırımcıların paranın zaman değerini güncel olarak tutmak istemlerindendir (Kalmanbetova, 2010:7). Hisse senetleri piyasaları özellikle gelişmekte olan ülke piyasaları risk unsurunu sürekli göz önünde bulundurmak durumundadırlar. Korku Endeksi olarak VIX göstergesi ile hisse senetleri fiyatları arasında anlamlı ilişki bulunan birçok çalışma literatürde bulunmaktadır (Çıtak, 2019:683). Özellikle jeopolitik ve politik risklerin finansal piyasalar üzerinde yabancı ve yerli yatırımcılar açısından dikkatle izlendiği görülmektedir. CDS (Kredi Temerrüt Takası) ise diğer bir risk göstergesi olarak çalışmada bağımsız değişken olarak kullanılmıştır. CDS primleri yabancı yatırımcılar açısından yatırım yapmak istedikleri ülke hakkında öncü bilgi olarak kullanılan bir göstergedir. CDS her ne kadar ülkeye ait tahvil risklerini gösterse de Hisse sentlerinin fiyatları üzerinde anlamlı bir etkiye sahip olduğu yapılan çalışmalardan görülmektedir. Çalışmada kontrol değişkeni olarak kullanılan toplam mevduat ve verilen toplam krediler değişkenleri bankacılık sektörü için iç faktörleri oluşturmaktadır. Bankacılık sektörünün hisse senetleri ile anlamlı bir ilişkisinin olduğu düşüncesi ile çalışmada kontrol değişkeni olarak yer almıştır.

\section{1 Çalışmanın Yöntemi}

CDS primleri, Euro, Dolar, Altın ve VIX'in bankacılık endeksi üzerindeki uzun ve kısa dönemli asimetrik etkisini incelemek için (1) nolu denklem oluşturulmuştur.

$$
\begin{gathered}
\text { Endeks }_{t}=\beta_{0}+\beta_{1}\left(\text { CDS }_{t}\right)+\beta_{2}\left(\text { Euro }_{t}\right)+\beta_{3}\left(\text { Dolar }_{t}\right)+\beta_{4}\left(\text { Altin }_{t}\right) \\
+\beta_{5}\left(\text { VIX }_{t}\right) \\
+\beta_{6}\left(E_{t}\right)+\beta_{7}\left(F O_{t}\right)+\beta_{8}\left(\text { TMM }_{t}\right)+\beta_{9}\left(T K_{t}\right)+u_{t}
\end{gathered}
$$


Yukarıda da belirtildiği gibi, EO, FO TMM ve TK değişkenleri kontrol değişkenler olarak modele eklenmiştir. Zaman serisi ile yapılan çalışmalarda, genellikle serilerin lineer davranış gösterdiği varsayımı altında analizler yapılmaktadır. Ancak, gerçekte seriler sürekli artış veya azalış trendi göstermemektedir (Çıtak ve Kendirli, 2019:648). Böyle bir durumda, NARDL modelinin kullanılması daha uygun olacaktır. (1) nolu denklemi kullanarak, bağımsız değişkenlerin bağımlı üzerindeki asimetrik ilişkinin varlığını belirlemek için aşağıdaki formül (2) oluşturulmuştur.

Endeks $_{t}$

$$
\begin{aligned}
& =f\left(E O, F O, T M M, T K, C D S^{+}, C D S^{-}, \text {Euro }^{+}, \text {Euro }^{-}, \text {Dolar }^{+}, \text {Dolar }^{-},\right. \\
& \text {Altin } \left.^{+}, \text {Altin }^{-}, V X^{+}, \text {VIX }^{-}\right)
\end{aligned}
$$

(2) nolu denklemi (1) nolu denklemle birleştirdiğimizde, kısa dönem katsayıları ile uzun dönem katsayılarını içeren (3) Nolu denklemi elde ederiz.

$$
\begin{aligned}
& \Delta \text { Endeks }_{t}=\alpha_{0}+\alpha_{1} \text { Endeks }_{t-1}+\alpha_{2} \text { EO }_{t}+\alpha_{3} F_{t}+\alpha_{4} \text { TMM }_{t}+\alpha_{5} \text { TK }_{t}+ \\
& \alpha_{6}^{+} \text {CDS }_{t-1}^{+}+\alpha_{7}^{-} \operatorname{CDS}_{t-1}^{-}+\alpha_{8}^{+} \text {Euro }_{t-1}^{+}+\alpha_{9}^{-} \text {Euro }_{t-1}^{-}+\alpha_{10}^{+} \text {Dolar }_{t-1}^{+}+ \\
& \alpha_{11}^{-} \text {Dolar }_{t-1}^{-}+\alpha_{12}^{+} \text {Altin }_{t-1}^{+}+\alpha_{13}^{-} \text {Altin }_{t-1}^{-}+\alpha_{14}^{+} \text {VIX }_{t-1}^{+}+\alpha_{15}^{-} \text {VIX }_{t-1}^{-}+ \\
& \sum_{k=1}^{p} \theta_{1} \Delta \text { Endeks }_{t-1}+\sum_{k=0}^{q_{1}}\left(\vartheta_{1}^{+} \Delta C D S_{t}^{+}+\vartheta_{1}^{-} \Delta C D S_{t}^{-}\right)+\sum_{k=0}^{q_{2}}\left(\gamma_{1}^{+} \Delta \text { Euro }_{t}^{+}+\right. \\
& \left.\gamma_{1}^{-} \Delta \text { Euro }_{t}^{-}\right)+\sum_{k=0}^{q_{3}}\left(\mu_{1}^{+} \Delta \text { Dolar }_{t}^{+}+\mu_{1}^{-} \text {Dolar }_{t}^{-}\right)+\sum_{k=0}^{q_{4}}\left(\rho_{1}^{+} \Delta \text { Altin }_{t}^{+}+\right. \\
& \left.\rho_{1}^{-} \text {Altin }_{t}^{-}\right)+\sum_{k=0}^{q_{5}}\left(\tau_{1}^{+} \Delta \text { VIX }_{t}^{+}+\tau_{1}^{-} \text {VIX }_{t}^{-}\right)+\varepsilon_{t}
\end{aligned}
$$

(3) eşitlikte yer alan $\alpha^{\prime}$ lar parametreli değişkenlere ait uzun dönem katsayıları gösterirken $\theta, \vartheta, \gamma, \mu, \rho$ ve $\tau$ parametleri, modele ait kısa dönem katsayıları ifade etmektedir.

ARDL modelinde olduğu gibi, NARDL modelini de oluştururken birtakım ön testler yapılmaktadır. Öncelikle, birim kök testleri kullanılarak, değişkenlerin hangi mertebeden (derece) bütünleşik oldukları belirlenir. Burada önemli olan, birim kök testi yapılan değişkenlerin hiç birinin 2. mertebeden veya daha yüksek dereceden bütünleşik olmadığını saptamaktır. Daha sonra, denklem (3)'te yer alan değişkenlere ait en uygun gecikme uzunlukları tespit edilerek, modelin otokorelasyon, değişen varyans ve normallik varsayımları kontrol edilir.

Tüm varsayımların sağlandıktan sonra, değişkenler arasında uzun dönemde eşbütünleşme olup olmadığı Wald testi yardımıyla (4a) ve (4b) yer alan hipotezler yardımıyla kontrol edilir.

$$
\begin{array}{ll}
H_{0}: & \alpha_{1}=\alpha_{2}=\alpha_{3}=\cdots=\alpha_{15}^{-} \\
\mathrm{H}_{1}: & \alpha_{1} \neq \alpha_{2} \neq \alpha_{3} \neq \cdots \neq \alpha_{15}^{-}
\end{array}
$$


Wald testi yardımıyla elde edilecek F istatistik değeri, Narayan (2005) tarafindan hesaplanan alt ve üst limit değerleri ile karşılaştırılır.

Yapılan testler sonucunda eşbütünleşmenin varlığı tespit edilirse, asimetrik etkisine incelenen değişkenlerin bağımlı değişken üzerinde asimetrik bir etkiye sahip olup olmadığı, aşağıdaki (5a)-(5e) hipotezler yardımıyla test edilir.

CDS için: $\quad H_{0}:-\frac{\alpha_{6}^{+}}{\alpha_{1}}=-\frac{\alpha_{7}^{-}}{\alpha_{1}}, \quad H_{1}:-\frac{\alpha_{6}^{+}}{\alpha_{1}} \neq-\frac{\alpha_{7}^{-}}{\alpha_{1}}$

Euro için: $\quad H_{0}:-\frac{\alpha_{8}^{+}}{\alpha_{1}}=-\frac{\alpha_{9}^{-}}{\alpha_{1}}, \quad H_{1}:-\frac{\alpha_{8}^{+}}{\alpha_{1}} \neq-\frac{\alpha_{9}^{-}}{\alpha_{1}}$

Dolar için: $\quad H_{0}:-\frac{\alpha_{10}^{+}}{\alpha_{1}}=-\frac{\alpha_{11}^{-}}{\alpha_{1}}, \quad H_{1}:-\frac{\alpha_{10}^{+}}{\alpha_{1}} \neq-\frac{\alpha_{11}^{-}}{\alpha_{1}}$

Atın için: $\quad H_{0}:-\frac{\alpha_{12}^{+}}{\alpha_{1}}=-\frac{\alpha_{13}^{-}}{\alpha_{1}}, \quad H_{1}:-\frac{\alpha_{12}^{+}}{\alpha_{1}} \neq-\frac{\alpha_{13}^{-}}{\alpha_{1}}$

VIX için: $\quad H_{0}:-\frac{\alpha_{14}^{+}}{\alpha_{1}}=-\frac{\alpha_{15}^{-}}{\alpha_{1}}, \quad H_{1}:-\frac{\alpha_{14}^{+}}{\alpha_{1}} \neq-\frac{\alpha_{15}^{-}}{\alpha_{1}}$

Son olarak, her bir uzun dönem katsayısının anlamlı olup olmadığını sınamak için aşağıdaki (6a)- (6p) formülündeki hipotezler kurularak test edilir.

$$
\begin{array}{lll}
\text { EO: } & H_{0}:-\frac{\alpha_{2}}{\alpha_{1}}=0, & H_{1}:-\frac{\alpha_{2}}{\alpha_{1}} \neq 0 \\
\text { FO: } & H_{0}:-\frac{\alpha_{3}}{\alpha_{1}}=0 & H_{1}:-\frac{\alpha_{3}}{\alpha_{1}} \neq 0 \\
\text { TMM: } & H_{0}:-\frac{\alpha_{4}}{\alpha_{1}}=0, & H_{1}:-\frac{\alpha_{4}}{\alpha_{1}} \neq 0 \\
\text { TK: } & H_{0}:-\frac{\alpha_{5}}{\alpha_{1}}=0, & H_{1}:-\frac{\alpha_{5}}{\alpha_{1}} \neq 0 \\
\text { CDS }^{+}: & H_{0}:-\frac{\alpha_{6}^{+}}{\alpha_{1}}=0, & H_{1}:-\frac{\alpha_{6}^{+}}{\alpha_{1}} \neq 0 \\
\text { CDS }^{-}: & H_{0}:-\frac{\alpha_{7}^{7}}{\alpha_{1}}=0, & H_{1}:-\frac{\alpha_{7}^{-}}{\alpha_{1}} \neq 0 \\
\text { Euro }^{+}: & H_{0}:-\frac{\alpha_{8}^{+}}{\alpha_{1}}=0, & H_{1}:-\frac{\alpha_{8}^{+}}{\alpha_{1}} \neq 0 \\
\text { Euro }^{-}: & H_{0}:-\frac{\alpha_{9}^{-}}{\alpha_{1}}=0, & H_{1}:-\frac{\alpha_{9}^{-}}{\alpha_{1}} \neq 0 \\
\text { Dolar }^{+}: & H_{0}:-\frac{\alpha_{10}^{+}}{\alpha_{1}}=0, & H_{1}:-\frac{\alpha_{10}^{+}}{\alpha_{1}} \neq 0 \\
\text { Dolar }^{-}: & H_{0}:--\frac{\alpha_{11}^{-}}{\alpha_{1}}=0, & H_{1}:-\frac{\alpha_{11}^{-}}{\alpha_{1}} \neq 0 \\
\text { Altin }^{+}: & H_{0}:-\frac{\alpha_{12}^{+}}{\alpha_{1}}=0, & H_{1}:-\frac{\alpha_{12}^{+}}{\alpha_{1}} \neq 0 \\
\text { Altin }^{-}: & H_{0}:-\frac{\alpha_{13}^{-}}{\alpha_{1}}=0, & H_{1}:-\frac{\alpha_{13}^{-}}{\alpha_{1}} \neq 0 \\
\text { VIX }^{+}: & H_{0}:-\frac{\alpha_{14}^{+}}{\alpha_{1}}=0, & H_{1}:-\frac{\alpha_{14}^{+}}{\alpha_{1}} \neq 0 \\
\text { VIX }^{-}: & H_{0}:-\frac{\alpha_{15}^{-}}{\alpha_{1}}=0, & H_{1}:-\frac{\alpha_{15}^{-}}{\alpha_{1}} \neq 0
\end{array}
$$


Bankacıllk Endeksi İle Seçilmiş Makroekonomik Faktörler Arasındaki Asimetrik İlişki

\subsection{Analiz Sonuçları}

Analiz sonuçlarından ilk olarak değişkenlere ait tanımlayıcı istatistikler verilmiştir. Tablo 3'de verilen sonuçlara göre, çalışmanın bağımlı değişkeni olan Endeks değeri en yüksek ortalamaya sahiptir.

Tablo 3: Değişkenlere Ait Tanımlayıcı İstatistikler

\begin{tabular}{lcccccccccc}
\hline & ALTN & CDS & K.TOPL & FAIZ & T.MEV & VIX & DOL & ENKS & ENF & EURO \\
Ortalama & 7.060 & 5.390 & 20.388 & 11.472 & 20.475 & 2.864 & 0.782 & 11.686 & 5.379 & 1.0169 \\
Medyan & 7.172 & 5.353 & 20.448 & 9.687 & 20.462 & 2.791 & 0.601 & 11.754 & 5.358 & 0.891 \\
Mnimum & 6.248 & 4.769 & 18.728 & 5.264 & 19.289 & 2.252 & 0.157 & 10.732 & 4.805 & 0.448 \\
Msimum & 7.512 & 6.325 & 21.674 & 22.852 & 21.646 & 4.092 & 1.859 & 12.154 & 6.100 & 2.026 \\
Std Hata & 0.301 & 0.305 & 0.879 & 4.504 & 0.668 & 0.360 & 0.472 & 0.285 & 0.346 & 0.398 \\
Çarpıklık & -0.970 & 0.439 & -0.189 & 0.755 & 0.021 & 0.956 & 0.731 & -1.023 & 0.248 & 0.858 \\
Basıkık & 2.945 & 2.833 & 1.731 & 2.334 & 1.884 & 3.805 & 2.385 & 3.844 & 2.116 & 2.757 \\
Gözlem & 169 & 169 & 169 & 169 & 169 & 168 & 169 & 169 & 169 & 169 \\
\hline
\end{tabular}

NARDL modelini tahmin etmeden önce, modelde kullanılan değişkenlerin bütünleşme derecelerinin $I(2)$ olmadığından emin olunmalıdır, aksi takdirde tahmin edilen model sonuçları sahte (spurious) olabilir. Tablo 4'de ilgili değişkenlerin tahmin edilen birim kök testi sonuçları, Augmented Dickey-Fuller (ADF) testi yardımıyla analiz edilmiştir. Elde edilen sonuçlara göre, değişkenlerden tümünün düzey seviyesinde durağan olduğu görülmektedir.

Tablo 4: ADF Birim Kök Testi Sonuçlarl

\begin{tabular}{lcc}
\hline \multicolumn{1}{c}{ ADF } \\
\hline Değişkenler & t- İstatistik & Prob. \\
\hline ENDEKS & $-13,69979$ & 0,0000 \\
Altın & -14.69789 & 0,0000 \\
CDS & -13.82500 & 0,0000 \\
KREDITOPL & -10.61290 & 0,0000 \\
FAIZ & -6.916837 & 0,0000 \\
TOPLMEV & -14.37647 & 0,0000 \\
DOL & -11.62296 & 0,0000 \\
EURO & -12.39080 & 0,0000 \\
ENF & -7.656020 & 0,0000 \\
VIX & -15.87674 & 0,0000 \\
\hline
\end{tabular}


Değişkenlere ait birim kökler kontrol edildikten sonra, uzun dönem ve kısa dönemde değişkenler arasında eşbütünleşme olup olmadığı Wald testi yardımıyla incelenmiştir. Narayan (2005) tarafından hesaplanan alt ve üst limit değerleri ile eşbütünleşmenin varlığının tespiti için kullanılan F istatistik değerleri Tablo 5 'te verilmiştir.

Tablo 5. NARDL Eşbütünleşme Sonuçları

\begin{tabular}{lcccc}
\hline & F-istatistiği & AltSınır & ÜstSınır & Sonuç \\
\hline Uzun Dönem NARDL Eşbütünleşme Test Sonuçları & \\
\hline $\begin{array}{l}\text { CDS, Euro, Dolar, Altın, VIX } \rightarrow \\
\text { Endeks }\end{array}$ & 7.090 & 2.355 & 3.500 & $\begin{array}{c}\text { Eşbütünleşme } \\
\text { vardır }\end{array}$ \\
\hline \multicolumn{5}{c}{ Kısa Dönem NARDL Eşbütünleşme Test Sonuçları } \\
\hline $\begin{array}{l}\text { CDS, Euro, Dolar, Altın, VIX } \rightarrow \\
\text { Endeks }\end{array}$ & 14.030 & 2.355 & 3.500 & $\begin{array}{c}\text { Eşbütünleşme } \\
\text { vardır }\end{array}$ \\
\hline
\end{tabular}

Elde edilen uzun dönem ve kısa dönem eş bütünleşme sonuçlarına göre $\mathrm{F}$ istatistik değerleri (7.090 ve 15.204$) \% 1$ anlamlılık düzeyinde eş bütünleşme bulunmuştur. Narayan (2005)'e göre alt ve üst sınır değeri sırasıyla 2.335 ve 3.500 belirlenmiş olup değerler alt ve üst sınırın üzerinde olduğundan değişkenler arasında hem uzun dönemli hem de kısa dönemli bir eş bütünleşme ilişkisinin varlığı tespit edilmiştir şeklinde yorumlanabilmektedir. Daha sonra, değişkenler arasında eş bütünleşme olgusu doğrulandıktan sonra, Shin et al. (2014) çalışması takip edilerek, her bir denklem için genelden özele yaklaşımı (general to specific approach) kullanılarak uzun dönem ve kısa dönem NARDL modelleri tahmin edilmiştir. Bankacılık endeksi ile bağımsız değişkenler arasında NARDL sonuçları Tablo 6' da verilmiştir.

Tablo 6. NARDL Testi Sonuçlarl

\begin{tabular}{cccc}
\hline Değişken & Katsayı & Standart Hata & t-ist [Olasılık] \\
\hline Sabit & 3.899 & 4.851 & $0.803[0.422]$ \\
\hline Endeks(-1) & -0.516 & 0.066 & $0.803[0.422]$ \\
\hline Dolar $^{+}(-1)$ & 0.275 & 0.140 & $1.960[0.052]$ \\
\hline Dolar $^{-}(-1)$ & -0.130 & 0.280 & $-0.464[0.642]$ \\
\hline Euro $^{+}(-1)$ & -0.399 & 0.188 & $-2.123[0.344]$ \\
\hline Euro $^{-}(-1)$ & -0.018 & 0.158 & $-0.119[0.905]$ \\
\hline CDS $^{+}(-1)$ & -0.199 & 0.062 & $-3.219[0.001]$ \\
\hline CDS $^{-}(-1)$ & -0.352 & 0.061 & $-5.736[0.000]$ \\
\hline VIX $^{+}(-1)$ & -0.024 & 0.025 & $-0.949[0.344]$ \\
\hline VIX $^{-}(-1)$ & -0.049 & 0.028 & $-1.708[0.089]$ \\
\hline Altın $^{+}(-1)$ & -0.002 & 0.098 & $-0.027[0.978]$ \\
\hline Altın $^{-}(-1)$ & 0.358 & 0.061 & $-5.736[0.017]$ \\
\hline Enf & -0.363 & 0.360 & $-1.009[0.314]$ \\
\hline Faiz & -0.009 & 0.004 & $-2.214[0.028]$ \\
\hline
\end{tabular}


Bankacıllk Endeksi İle Seçilmiş Makroekonomik Faktörler Arasındaki Asimetrik İlişki

Tablo 6 Devamı: NARDL Testi Sonuçları

\begin{tabular}{|c|c|c|c|}
\hline Toplam Kredi & -0.370 & 0.287 & $-1.980[0.049]$ \\
\hline Toplam Mevduat & 0.562 & 0.367 & $1.530[0.128]$ \\
\hline$R^{2}$ & 0.728 & Adj. $-R^{2}$ & 0.662 \\
\hline F-statistic & $11.000[0.000]$ & $\chi_{\text {Değ.Varn. }}$ & 0.772 \\
\hline 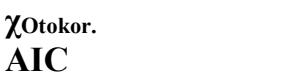 & $\begin{array}{r}0.536 \\
-2.709\end{array}$ & $\begin{array}{l}\chi_{\text {Norm }} \\
\text { DW }\end{array}$ & $\begin{array}{l}0.414 \\
2.034\end{array}$ \\
\hline
\end{tabular}

Not: Modellerin güvenirliklerini test etmek için, Breusch-Godfrey Serisel Korelasyon LM testi $\left(\chi_{\mathrm{AC}}\right)$, White Değişen Varyans testi $\left(\chi_{\mathrm{DV}}\right)$, ve Normallik testi $\left(\chi_{\text {NORM }}\right)$ kullanılmıştır. Söz konusu diagnostik testlerin sonuçlarına göre, 0.05 anlamlılık düzeyinde modellerde normallik, otokorelasyon ve değișen varyans sorunları bulunmamaktadır. En uygun NARDL modelinin elde edilmesinde, maksimum gecikme uzunluğu AIC değerine göre 4 olarak belirlenmiştir.

Tablo 7. Uzun Dönem NARDL Modeli Sonuçları

\begin{tabular}{ccc}
\hline Değişken & Katsayı & [Olasılık] \\
\hline Dolar $^{+}$ & -0.534 & 0.470 \\
\hline Dolar $^{-}$ & -0.252 & 0.665 \\
\hline Euro $^{+}$ & -0.774 & 0.524 \\
\hline Euro $^{-}$ & -0.036 & 0.906 \\
\hline CDS $^{+}$ & -0.386 & 0.431 \\
\hline CDS $^{-}$ & -0.682 & 0.412 \\
\hline VIX $^{+}$ & -0.047 & 0.578 \\
\hline VIX $^{-}$ & -0.095 & 0.450 \\
\hline Altın $^{+}$ & -0.005 & 0.978 \\
\hline Altın & 0.473 \\
\hline Enf & -0.639 & 0.526 \\
\hline Faiz & -0.204 & 0.419 \\
\hline Toplam Kredi & -0.018 & 0.507 \\
\hline Toplam Mevduat & -0.717 & 0.586 \\
\hline
\end{tabular}

Tablo 7'de uzun dönemde her bir katsayının anlamlı olup olmadığı yukarıda açıklanan formüller yerine konularak analiz yapılmıştır. Çalışma sonucunda uzun dönem test sonuçlarına göre değişkenler arasında $\% 1, \% 5$ ve $\% 10$ anlamlılık düzeyinde istatistiksel bir ilişki bulunamamıştır. Uzun dönem asimetrisi incelenen değişkenlerin Wald tesit $F$ istatistik değeri(8.119) ve $p$ olasılık değeri (0.000) çıkmış olup sonuçlara göre uzun dönemde VIX, Dolar, Euro, CDS ve Altın değişkeninin Bankacılık Endeksi üzerinde asimetrik etkisi olduğu bulunmuştur.

Tablo 8. Klsa Dönem NARDL Sonuçlarl

\begin{tabular}{lccc}
\hline Değişken & Katsayı & Std. Hata & t-ist[Olasılık] \\
\hline$\Delta$ Endeks $^{-}$ & -0.134 & 0.058 & $-2.306[0.022]$ \\
\hline$\Delta$ Dolar $^{+}$ & -0.966 & 0.190 & $-5.083[0.000]$ \\
\hline$\Delta$ Dolar $^{+}(-3)$ & 0.495 & 0.242 & $2.046[0.042]$ \\
\hline$\Delta$ Dolar $^{-}$ & -0.732 & 0.394 & $-1.858[0.065]$ \\
\hline$\Delta$ Dolar $^{-}(-1)$ & -0.749 & 0.345 & $-2.168[0.031]$ \\
\hline$\Delta$ Dolar $^{-}(-2)$ & -0.950 & 0.340 & $-2.789[0.006]$ \\
\hline$\Delta$ Euro $^{-}$ & -0.990 & 0.374 & $-2.634[0.009]$ \\
\hline
\end{tabular}


Tablo 8 Devamı. Klsa Dönem NARDL Sonuçları

\begin{tabular}{lccc}
\hline$\Delta$ Euro $^{+}(-2)$ & -0.480 & 0.178 & $-2.698[0.007]$ \\
\hline$\Delta$ Euro $^{+}(-3)$ & -0.407 & 0.254 & $-1.599[0.112]$ \\
\hline$\Delta$ Euro $^{-}(-3)$ & -0.775 & 0.330 & $-2.341[0.020]$ \\
\hline$\Delta$ Euro $^{+}(-4)$ & -0.435 & 0.182 & $-2.388[0.018]$ \\
\hline$\Delta$ CDS $^{-}$ & -0.381 & 0.088 & $-4.327[0.000]$ \\
\hline$\Delta$ CDS $^{-}(-2)$ & 0.285 & 0.083 & $3.432[0.000]$ \\
\hline$\Delta$ CDS $^{-}(-4)$ & 0.181 & 0.067 & $2.692[0.008]$ \\
\hline$\Delta \operatorname{VIX}^{-}(-1)$ & 0.110 & 0.045 & $2.427[0.016]$ \\
\hline$\Delta$ Altin $^{+}(-4)$ & -0.778 & 0.187 & $-4.147[0.000]$ \\
\hline$\Delta$ Altin $^{-}(-4)$ & 0.591 & 0.215 & $2.750[0.006]$ \\
\hline
\end{tabular}

Tablo 8'de kısa dönem asimetrik ilişki sonuçlarına göre, değişkenlerde meydana gelen değişimler bankacılık endeksi üzerinde asimetrik bir etkiye sahip olduğu görülmüştür. Kısa dönem asimetrik ilişkinin varlı̆̆ sonuçlarına göre değerlendirilmektedir. Yapılan Wald testi sonuçlarına göre $F$ istatistik değeri (4.186) ve p olasılık değeri ise $(0,000)$ çıkmıştır. Bu sonuçlar kısa dönemli asimetrik ilişkinin varlığını kanıtlamaktadır. Kontrol değişkeni olarak kullanılan Faiz oran1, Enflasyon Oran1, Verilen Toplam Krediler ve Toplam mevduat bu ayrımın dışında tutulmuştur. Denklem 4'de gösterildiği üzere Bankacıl1k endeksini Dolar (-0,534), Euro (-0,0774), CDS (-0,386), VIX (-0.047) ve Altın (-0.005) pozitif ayrımda uzun dönemli asimetrik bir ilişki bulunmuştur. Negatif ayrımda ise Bankacilık Endeksi üzerine CDS(-0.682), VIX(-0.095), Altın(-0.693), Dolar(-0,252), Euro(-0,036) uzun dönemli asimetrik bir ilişki bulunmuştur. Ayrıca çalışmada kısa dönemli asimetrik ilişki de bulunmuştur (Layenge ve Zumwalt, 1980; Booth and Officer 1985; Akella and Chen 1990; Scott and Peterson, 1986).

\section{Sonuç}

Gelişmekte olan ekonomilerde lokomotif görevi gören bankacıllk sektörü, ülkelerin büyümesi ve piyasaya sunduğu imkânlar neticesinde önemli sektörlerden biri olarak kabul edilmektedir. Literatür çalışmalarında önemli bir yer tutan bankacılık sektörü üzerine oldukça fazla çalışma yapılmıştır. Çalışmalar genellikle banka performansı ve hisse senedi fiyat ve getiri üzerine yoğunlaşmaktadır. Hisse senedinin fiyatı gelecekte sağlayacağı nakit akışının iskonto edilmiş haline eşittir. İskonto oranı ise genellikle piyasa faiz oranı (risksiz faiz oranı) ve risk primine bağlı olarak değişmektedir. Ancak hisse senetleri alım satımın yapıldığı pazarın etkinlik durumuna göre de değişmektedir. Etkin piyasalar hipotezine göre zayıf formda etkin piyasalarda piyasaya yansıyan bilgiler fiyatlar üzerinde etkili olabilmektedir. Buradan hareketle hisse senetleri makroekonomik değişkenlerden etkilenebilmektedir. Literatür incelemelerinde makroekonomik değişkenler ile hisse senedi fiyatı arasında yapılan çalışmalar farklılık göstermektedir. Bu farklılıkların temel sebebi kullanılan analiz 
yöntemleri ve ülkeye ait pazarın etkinlik formu olarak açıklanabilmektedir. Zayıf formda etkin olan Türkiye'de hisse fiyatları kamuya açıklanan bilgilerden etkilenebilmektedir. Bu kapsamda bu teorinin doğruluğunu test etmek ve değişkenlerin bankacılık endeksi üzerinde meydana getirebileceği olası etkileri ölçmek amacıyla Borsa İstanbul Bankacılık endeksi kapanış fiyatları ile seçilmiş makroekonomik değişkenler literatrüde henüz kullanılmaya başlanılan amacıyla Doğrusal Olmayan Gecikmesi Dağıtılmış Oto Regresif Model (NARDL) modeli ile test edilmiştir. Yapılan analizler sonucunda uzun dönemli asimetrik bir ilişki bulunamamış, kısa dönemli asimetrik bir ilişki bulunmuştur. Çalışmada kullanılan yöntem gereği değişkenlerin negatif değerleri de çalışmaya bağımsız değişken olarak eklenmiş ve VIX, CDS ve Altın, Dolar ve Euro bağımsız değişkenleri ile Bankacılık Endeksi arasında uzun dönemli bir asimetrik ilişki bulunmuştur. Çalışmanın sonuçları literatürle örtüşmektedir. Çalışma sonrasında yapılacak çalışmalara yöntemsel bir farklılık açısından çeşitlilik sağlamakta olup, Bankacılık endeksini etkileyen değişkenlerin İç ve dış olarak ayrıma tabi tutulması ve hisse fiyatına etkisinin bir arada değerlendirilmesinin özellikle bilanço dışı işlemlerin ve teknolojik yeniliklere açık olan bankaların incelenmesinin literatüre önemli katkılar yapacağı düşünülmektedir.

\section{Kaynaklar}

Akella, S. R., and Chen, S. J. (1990). Interest Rate Sensitivity of Bank Stock Returns: Specification Effects and Structural Changes. Journal of Financial Research, 13(2), 147-154.

Al-Jafari, M. K. (2011). Testing the Weak-Form Efficiency of Bahrain Securities Market. International Research Journal of Finance and Economics, 72(1), 14-24.

Booth, J. R., and Officer, D. T. (1985). Expectations, Interest Rates, and Commercial Bank Stocks. Journal of Financial Research, 8(1), 51-58.

Chance, D. M., and Lane, W. R. (1980). A Re-Examination of Interest Rate Sensitivity in the Common Stocks of Financial İnstitutions. Journal of Financial Research, 3(1), 49-55.

Chen, N., Roll, R., and Ross, S. (1986). Economic Forces and the Stock Market. The Journal of Business, 59(3), 383-403. Retrieved January 13, 2020, from www.jstor.org/stable/2352710.

Çıtak, F., ve Kendirli, S . (2019). Petrol Fiyatlarının Döviz Kuru ve Hisse Senedi Getirileri Üzerindeki Asimetrik Etkisi: Türkiye Örneği. Finans Ekonomi ve Sosyal Araştırmalar Dergisi (FESA) , 4 (4) , 643-658 . DOI: 10.29106/fesa.658845

Çıtak, Ferhat (2019). An Empirical Investigation of Rational Speculative Bubble in the Turkish Stock Market. International Journal of Economics and Innovation, 5(2):247-262.

Doğukanlı, H. (2008). Uluslararası Finans, Genişletilmiş 2. Baskı, Adana: Karahan Yayınları. 
Elyak, A. (2008). İMKB 100 Endeksini Etkileyen Faktörlerin Ekonometrik Analizi.

Fama, E. F. (1981). Stock Returns, Real Activity,Inflation, and Money. The American economic review, 71(4), 545-565.

Fogler, H. R., John, R., and Tipton, J. (1981). Three Factors, Interest Rate Differentials and Stock Groups. The Journal of finance, 36(2), 323-335.

Gan, C., Lee, M., Yong, H. H. A., and Zhang, J. (2006). Macroeconomic Variables and Stock Market Interactions: New Zealand evidence. Investment Management and Financial Innovations, 3(4), 89101.

Isimbabi, Michael J. (1993). Risk Factors and the Stock Returns of Banking Firms. 0211-0211.

Johansen, S. (1988). Statistical Analysis of Cointegration Vectors. Journal of Economic Dynamics and Control, 12(2-3), 231-254.

Johansen, S., and Juselius, K. (1990). Some Structural Hypotheses in A Multivariate Cointegration Analysis of the Purchasing Power Parity And the Uncovered Interest Parity for UK (No. 90-05).

Kalmanbetova, M. (2010). Hisse Senedi Fiyatları ve Makroekonomik Değişkenler Arasındaki Nedensellik ve 2004-2009 Yılları Arasında Türkiye Uygulaması (Doctoral dissertation, Yüksek Lisans Tezi), İstanbul: İstanbul Üniversitesi Sosyal Bilimler Enstitüsü).

Koçbulut, Ö., ve altıntaş, H. (2016). İkiz Açıklar ve Feldstein-Horioka Hipotezi: OECD Ülkeleri Üzerine Yatay Kesit Bağımlılığı Altında Yapısal Kırılmalı Panel Eşbütünleşme Analizi. Erciyes Üniversitesi İktisadi ve İdari Bilimler Fakültesi Dergisi, (48), 145-174.

Lael Joseph, N., and Vezos, P. (2006). The Sensitivity of US Banks' Stock Returns to Interest Rate and Exchange Rate Changes. Managerial Finance, 32(2), 182-199.

Lee, B. 1992. Causal Relations Among Stock Returns, Interest Rates, Real Activity, and Inflation. Journal of Finance, 47: 1591-1604.

Lynge, M. J., and Zumwalt, J. K. (1980). An Empirical Study of the Interest Rate Sensitivity of Commercial Bank Returns: A Multi-index Approach. Journal of Financial and Quantitative analysis, 15(3), 731-742.

Moss, J. D., and Moss, G. J. (2010). Variables Explaining Bank Stock Prices. Journal of Applied Business Research (JABR), 26(4). https://doi.org/10.19030/jabr.v26i4.301.

Narayan, P. K. (2005). The Saving and Investment Nexus for China: Evidence from Cointegration tests. Applied economics, 37(17), 1979-1990.

Patra, T., and Poshakwale, S. (2006). Economic Variables and Stock Market Returns: Evidence From the Athens Stock Exchange. Applied Financial Economics, 16(13), 993-1005. 
Pesaran, M. H., Shin, Y., and Smith, R. J. (2001). Bounds Testing Approaches to The Analysis Of Level Relationships. Journal of Applied Econometrics, 16(3), 289-326.

Scott, W. L., and Peterson, R. L. (1986). Interest Rate Risk and Equity Values of Hedged and Unhedged Financial İntermediaries. Journal of Financial Research, 9(4), 325-329.

Sharma, G. D., and Mahendru, M. (2010). Impact of Macro-Economic Variables on Stock Prices in India. Global Journal of Management and Business Research, 10(7).

Sharma, G. D., and Mahendru, M. (2010). Impact of Macro-Economic Variables on Stock Prices in India. Global Journal of Management and Business Research, 10(7).

Shin, Y., Yu, B., and Greenwood-Nimmo, M. (2014). Modelling Asymmetric Cointegration and Dynamic Multipliers in a Nonlinear ARDL Framework. in Festschrift in Honor of Peter Schmidt (pp. 281-314). Springer, New York, NY.

Syzdykova, A. (2018). Petrol Fiyatlarının BRIC Ülkelerinin Borsalarına Etkisi/The Impact Of Oil Prices On BRIC Countries' Stock Markets. Uluslararası Ekonomi İşletme ve Politika Dergisi, 2(1), 1-20.

Ulusan, M. (2014). BIST-100 Getirileri, Dış Ticaret Açı̆̆ı ve Enflasyon Büyümesinin Nedensellik Açısından Analizi. TISK Academy/TISK Akademi, 9(18).

https://www.tbb.org.tr/Content/Upload/Dokuman/7639/Uluslararasi Karsilastir malar 2018.pdf

https://evds2.tcmb.gov.tr/ 


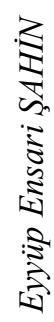
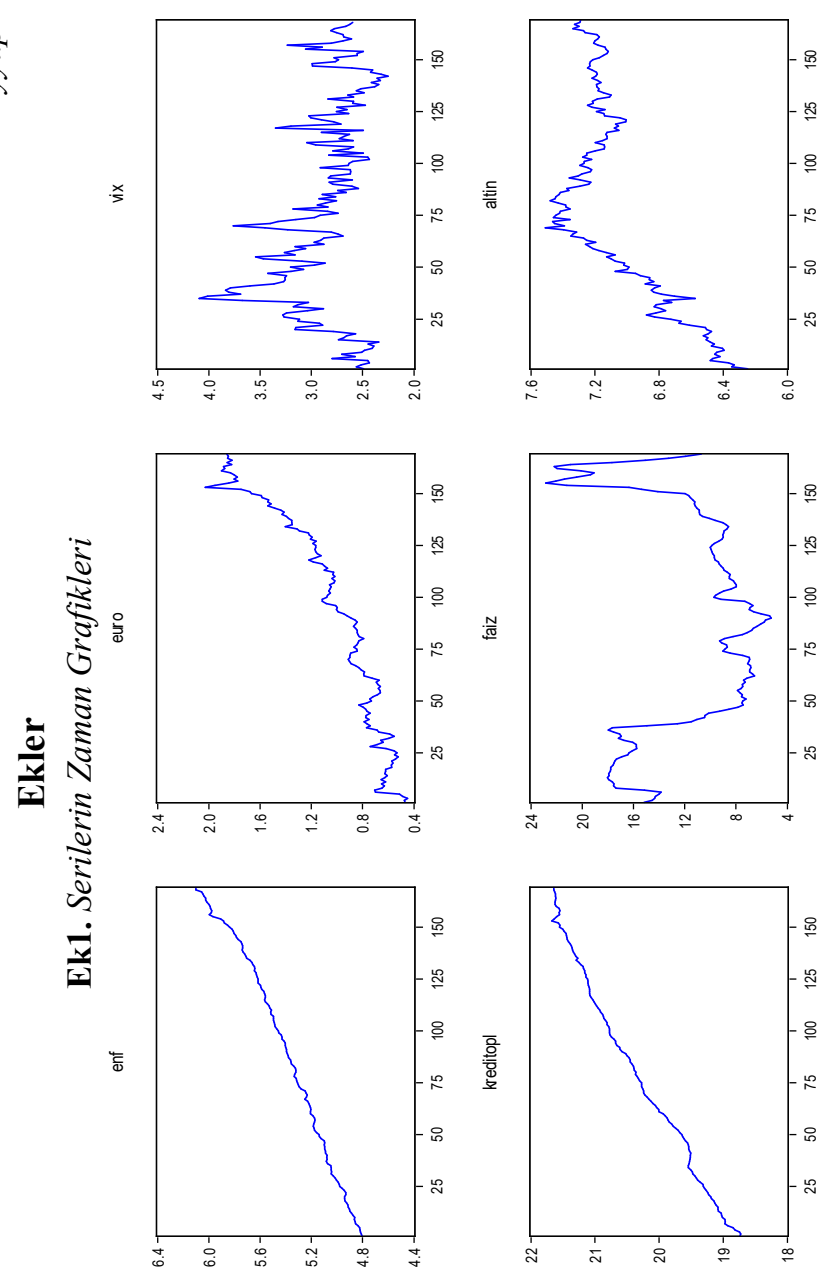

हे
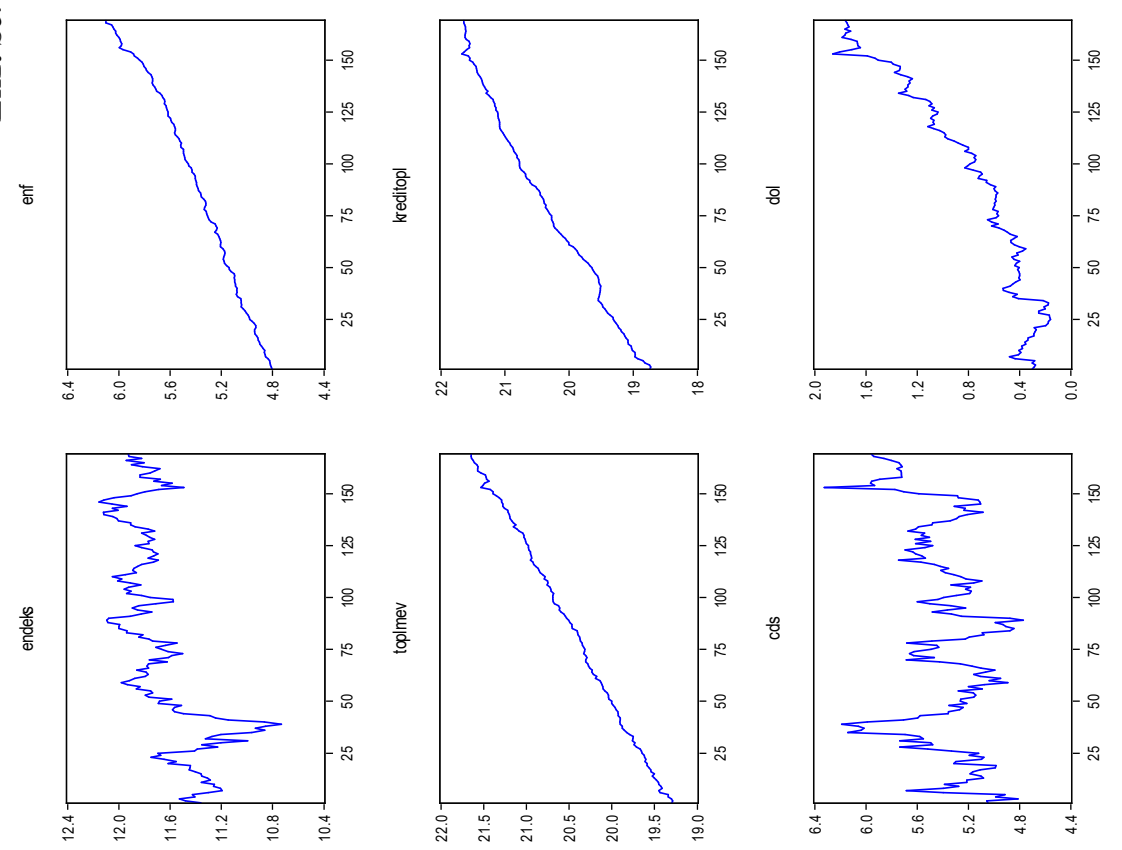

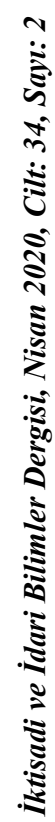

